\title{
MODELISASI NUMERIK ANALISIS GAYA LATERAL PADA PILE CAP DI TANAH KOHESIF
}

\author{
Darwin Halim ${ }^{1}$, Amelia Yuwono², dan Hendy Wijaya ${ }^{3}$ \\ ${ }^{1}$ Program Studi Sarjana Teknik Sipil, Universitas Tarumanagara, Jl. Letjen S. Parman No.1 Jakarta \\ Darwin.325160165@stu.untar.ac.id \\ ${ }^{2}$ Program Studi Sarjana Teknik Sipil, Universitas Tarumanagara, Jl. Letjen S. Parman No.1 Jakarta \\ yuwonoamelia@gmail.com \\ ${ }^{3}$ Program Studi Sarjana Teknik Sipil, Universitas Tarumanagara, Jl. Letjen S. Parman No.1 Jakarta \\ m.hendy@yahoo.com
}

Masuk: 06-07-2020, revisi: 19-07-2020, diterima untuk diterbitkan: 04-08-2020

\begin{abstract}
The foundation is a lower structure that serves to hold the burden that works from the structure above it the burden is passed on to the ground. The choice of foundation is based on the working load, the type of soil layer that supports the foundation, and the technology that can be used. Therefore, the performance of pile foundations in accepting lateral forces is important in geotechnical practice. In this journal, a centrifuged test model is tested to see the behavior of pile groups that are burdened by lateral loads. To find out the results of the trial, numerical modeling was carried out for the pile groups on clay. The clay soils modeled in this experiment were carried out under normally consolidated and over consolidated kaolin clay soils. The pile group model that was tested consisted of 2x2, 3x3, and $4 \times 4$ with a distance of center to center 3 times the width of the pile foundation. The results of this numerical analysis will be compared with the results of centrifuged tests that have been done before in other journals.
\end{abstract}

Keywords: pile foundation; lateral force; numerical modelling; pile groups

\section{ABSTRAK}

Fondasi merupakan struktur bawah yang berfungsi untuk menahan beban yang bekerja dari struktur bangunan diatasnya yang bebannya diteruskan ke tanah. Pemilihan fondasi didasarkan pada beban yang berkerja, jenis lapisan tanah yang menopang fondasi, serta teknologi yang dapat digunakan. Karena itu, kinerja fondasi tiang dalam menerima gaya lateral adalah hal yang penting dalam praktek geoteknik. Pada jurnal ini, sebuah model uji centrifuged di uji coba untuk melihat perilaku tiang kelompok yang terbebani oleh beban lateral. Untuk mengetahui hasil uji coba maka dilakukan modelisasi numerik untuk kelompok tiang pada tanah lempung. Tanah lempung yang dimodelkan dalam percobaan ini dilakukan pada tanah kondisi normally consolidated dan over consolidated kaolin clay. Model kelompok tiang yang di uji coba terdiri atas 2x2, 3x3, dan 4x4 dengan jarak spasi pusat ke pusat 3 kali dari lebar tiang fondasi. Hasil analisis numerik ini akan diperbandingkan dengan hasil uji centrifuged yang sudah pernah dilakukan sebelumnya pada jurnal lain.

Kata kunci: fondasi tiang; gaya lateral; modelisasi numerik; kelompok tiang

\section{PENDAHULUAN}

Pada dasarnya, semua struktur, bagaimana pun karakteristiknya, selalu didukung oleh fondasi karena fondasilah yang akan menyalurkan beban struktur secara keseluruhan ke dalam tanah. Pemilihan jenis fondasi yang akan digunakan sangat bergantung terhadap fungsi struktur yang akan ditopang, kondisi tanah dibawah struktur, serta perbandingan biaya fondasi terhadap biaya struktur secara keseluruhan. Pertimbangan fungsi struktur yang ditopang akan menunjukkan secara tidak langsung gambaran besar beban yang akan ditanggung oleh fondasi. Sementara itu, kondisi tanah di bawah struktur sangat berkaitan dengan perilaku tanah itu sendiri ketika menerima beban.

Fondasi tiang disamping menahan beban vertikal juga menahan beban horisontal seperti struktur lepas pantai yang menahan beban angin dan beban gelombang, dermaga pelabuhan yang menahan beban horisontal ketika kapal merapat pada dermaga, menara transmisi yang menahan beban angin dan bangunan gedung terutama bangunan bertingkat tinggi yang berada pada daerah gempa yang menahan beban gempa. Semua struktur bangunan tersebut memerlukan kapasitas daya dukung untuk menahan beban lateral atau horisontal. Karena itu pengetahuan mengenai 
sifat fondasi tiang yang menahan beban lateral menjadi sangat penting bagi geotechnical engineer. Penelitian mengenai grup tiang yang dibebani beban lateral dilapisan pasir dengan menggunakan alat centrifuge telah cukup banyak dilakukan oleh peneliti terdahulu seperti McVay et.al (1998) Namun masih sedikit penelitian mengenai kinerja grup tiang dilapisan lempung akibat pembebanan lateral.

Karena karakteristik lempung sangat berbeda dengan pasir maka sebuah seri pengujian dengan alat centrifuge dilakukan untuk menguji perilaku grup tiang yang dibebani gaya lateral statis dilapisan lempung normally consolidated. Hasil profil bending momen tiang dipresentasikan pada makalah ini dengan cukup rinci. Rumus empiris untuk grup tiang disajikan dalam makalah ini.

Penelitian dilakukan dengan menggunakan alat centrifuge mempunyai keuntungan lebih besar dibandingkan dengan menggunakan alat uji konvensional. Alat centrifuge dapat menghasilkan karakteristik tanah yang sama dengan karakteristik tanah yang sebenarnya sehingga tegangan efektif yang terjadi pada model, sama tegangan efektif prototip yang sebenarnya.

Pada Penelitian ini, Pemodelan Tiang terhadap beban lateral dilakukan dengan software berbasis geoteknik dengan kepala tiang kotak dimensi $84 \times 84 \mathrm{~cm}$. Sedangkan untuk konfigurasi tiang kelompok yang digunakan adalah 1 tiang, 2 tiang, 4 tiang, 9 tiang dan 16 tiang.

Tujuan dari Penelitian ini adalah untuk mengetahui besarnya gaya lateral maksimum yang dapat diterima kelompok tiang pada kondisi elastic, mengetahui besarnya displacement yang terjadi pada kelompok tiang yang diberikan gaya lateral maksimum pada kondisi elastic, mengetahui hasil simulasi numerik jika dibandingkan dengan uji laboratorium, mengetahui perbedaan antara normally consolidated clay dan over consolidated clay terhadap daya dukung lateral tiang.

\section{METODE PENELITIAN}

Sebuah rangka yang terbuat dari besi dengan dua buah actuator diletakkan diatas kontainer yang kemudian diikat dengan mur-baut. Actuator vertikal berada dibagian tengah atas dari rangka besi dan actuator horisontal diletakkan dibagian kiri bawah dari rangka besi. Pada kontainer juga terdapat kamera yang dihubungkan melalui CCTV ke ruang kontrol untuk memonitor jalannya percobaan. Dua buah LVDT (linier variable displacement transducer) digunakan untuk mengukur pergerakan atau perpindahan actuator vertikal dan horisontal. Model tiang terbuat dari pipa alumunium berlubang dengan penampang bujur sangkar dengan ukuran sisi 9,53 mm dan tebal 1,59 mm. Pada jurnal “Centrifuge Model Study of Laterally Loaded Pile Groups in Clay” ini, panjang model tiang adalah $260 \mathrm{~mm}$ dan yang terbenam dalam tanah $210 \mathrm{~mm}$. Panjang tiang prototip dengan tiang yang terbenam (embedded) adalah 14,7 m. Contoh model dapat dilihat pada Gambar 1.

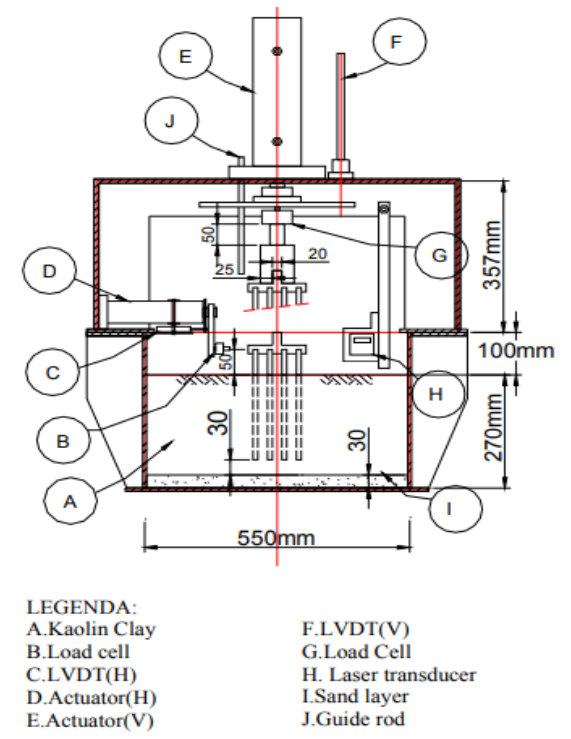

Gambar 1. Model set-up

Dari percobaan yang dilakukan pada jurnal “Centrifuge Model Study of Laterally Loaded Pile Groups in Clay” ini, didapatkan hasil displacement seperti yang ditunjukkan pada gambar 2. 

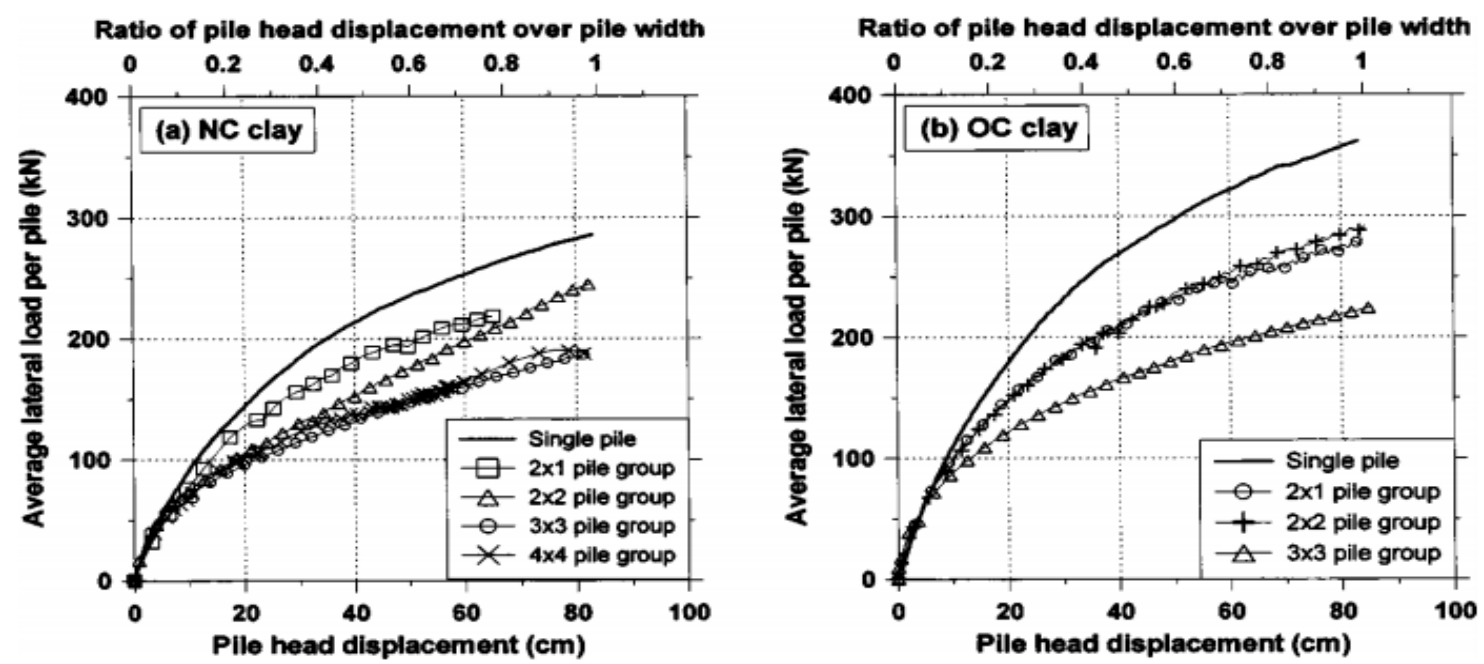

Gambar 2. Hasil uji coba displacement jurnal "Centrifuge Model Study of Laterally Loaded Pile Groups in Clay"

Selanjutnya, yang dilakukan oleh penulis adalah melakukan uji coba sesuai spesifikasi yang ada pada jurnal "Centrifuge Model Study of Laterally Loaded Pile Groups in Clay" (Ilyas, 2004) diuji pada program berbasis geoteknik untuk melihat hasil yang didapat apakah menyerupai seperti pada jurnal. Alur atau tahapan dari penelitian ini tertera dalam bentuk diagram pada Gambar 3 .

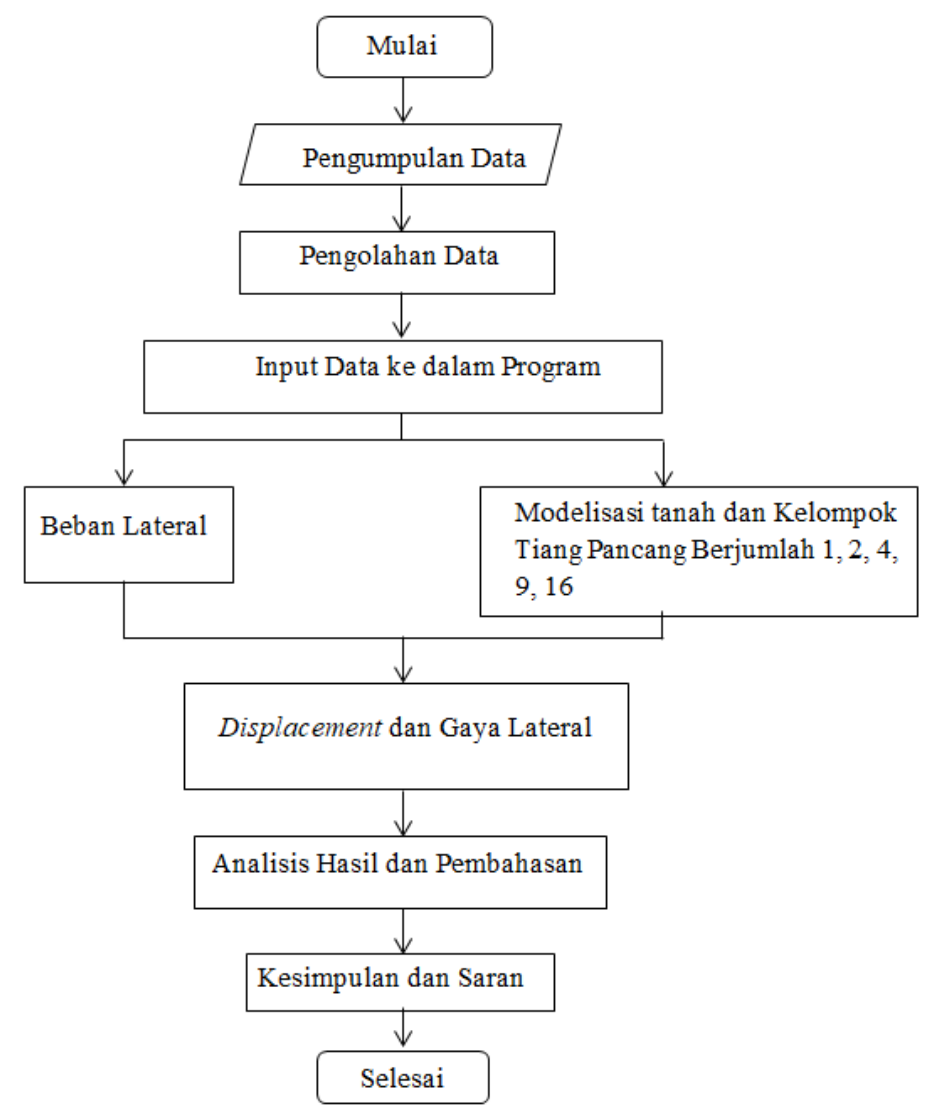

Gambar 3. Diagram alur penelitian 


\section{HASIL DAN PEMBAHASAN}

\section{Hasil analisis tiang pancang tunggal dan tiang kelompok pada tanah normally consolidated clay dan over consolidated clay}

Pada jurnal ini penulis menggunakan program berbasis geoteknik dengan menggunakan 2 jenis pemodelan tanah yaitu Hardening Soil dan Mohr Coulomb. Setelah dilakukan analisis, selanjutnya penulis melakukan back analysis dengan membandingkan hasil pada jurnal "Centrifuge Model Study of Laterally Loaded Pile Groups in Clay" dengan hasil pada program berbasis geoteknik yang diuji coba oleh penulis. Hasil yang didapat berupa kurva yang dibandingkan dengan kondisi tanah normally consolidated clay dan over consolidated clay . Dari analisis tersebut dapat kita bandingkan hasil displacement yang lebih baik pemodelan tanah antara Hardening Soil dan Mohr Coulomb.

Catatan: Pemodelan tanah hardening soil model untuk tanah normally consolidated dapat dilihat pada gambar $4 \mathrm{~s} / \mathrm{d}$ 8.

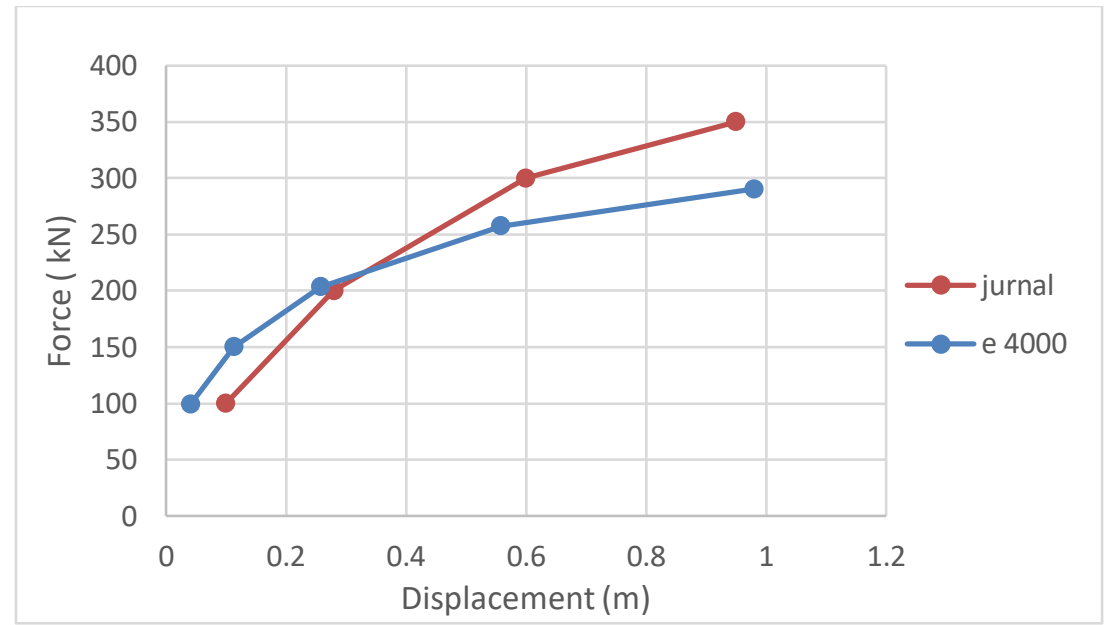

Gambar 4. Back analysis pushover 1 tiang dengan hardening soil model untuk tanah normally consolidated ( E tiang $=4000 \mathrm{kN} / \mathrm{m}^{2}$ )

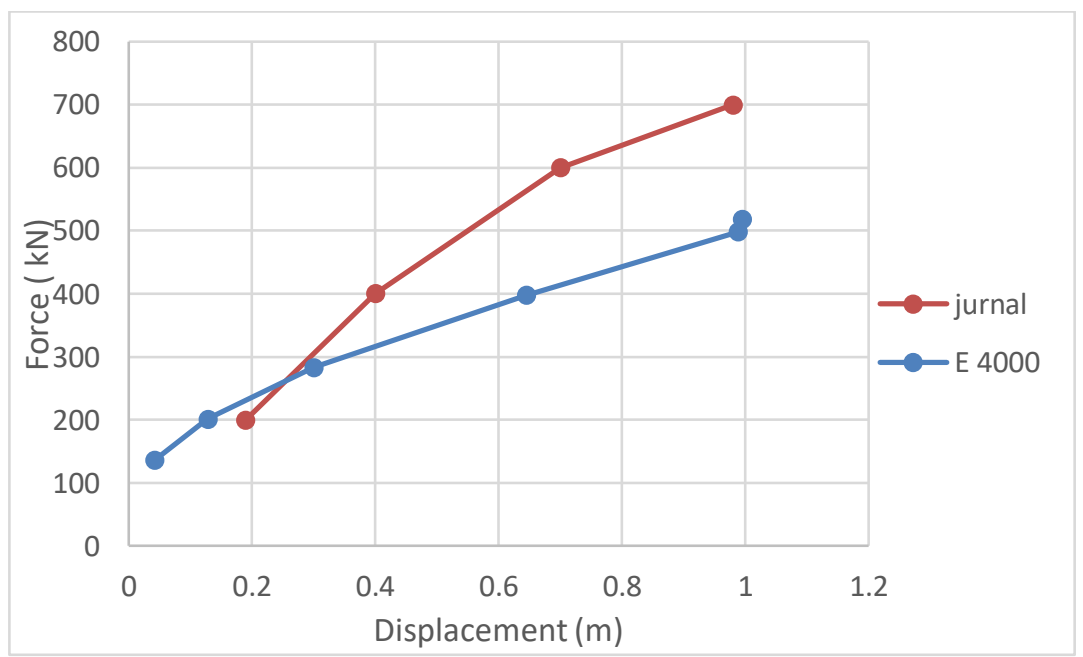

Gambar 5. Back analysis pushover 2 tiang dengan hardening soil model untuk tanah normally consolidated ( E tiang $=4000 \mathrm{kN} / \mathrm{m}^{2}$ ) 


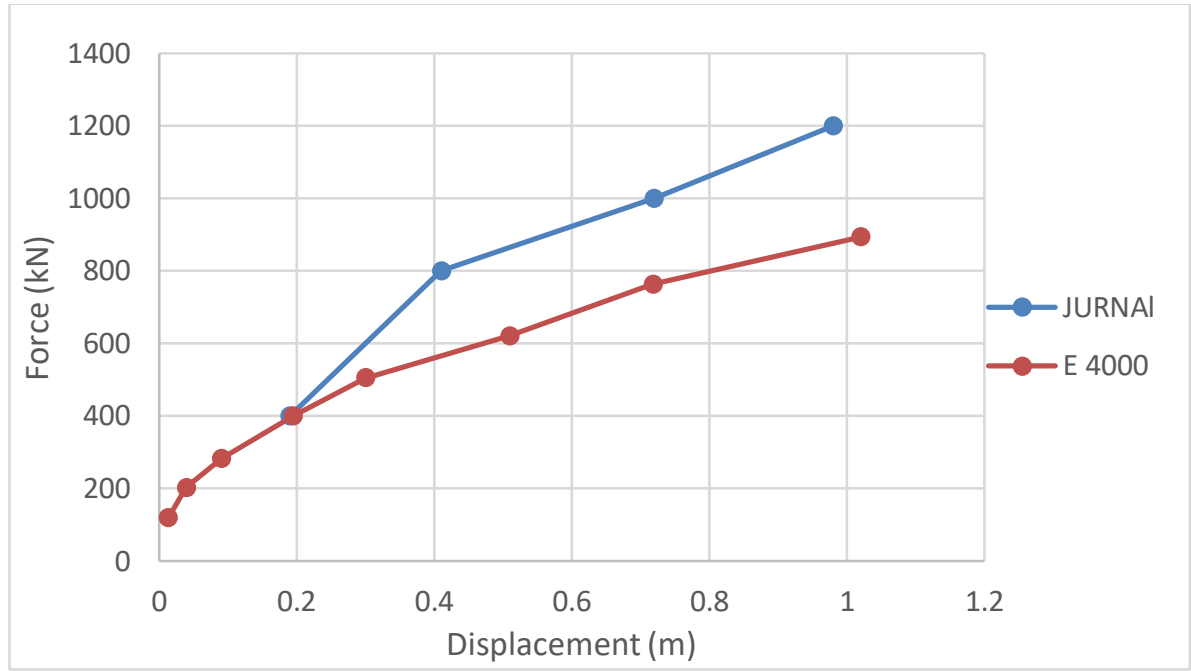

Gambar 6. Back analysis pushover 4 tiang dengan hardening soil model untuk tanah normally consolidated ( E tiang $=4000 \mathrm{kN} / \mathrm{m}^{2}$ )

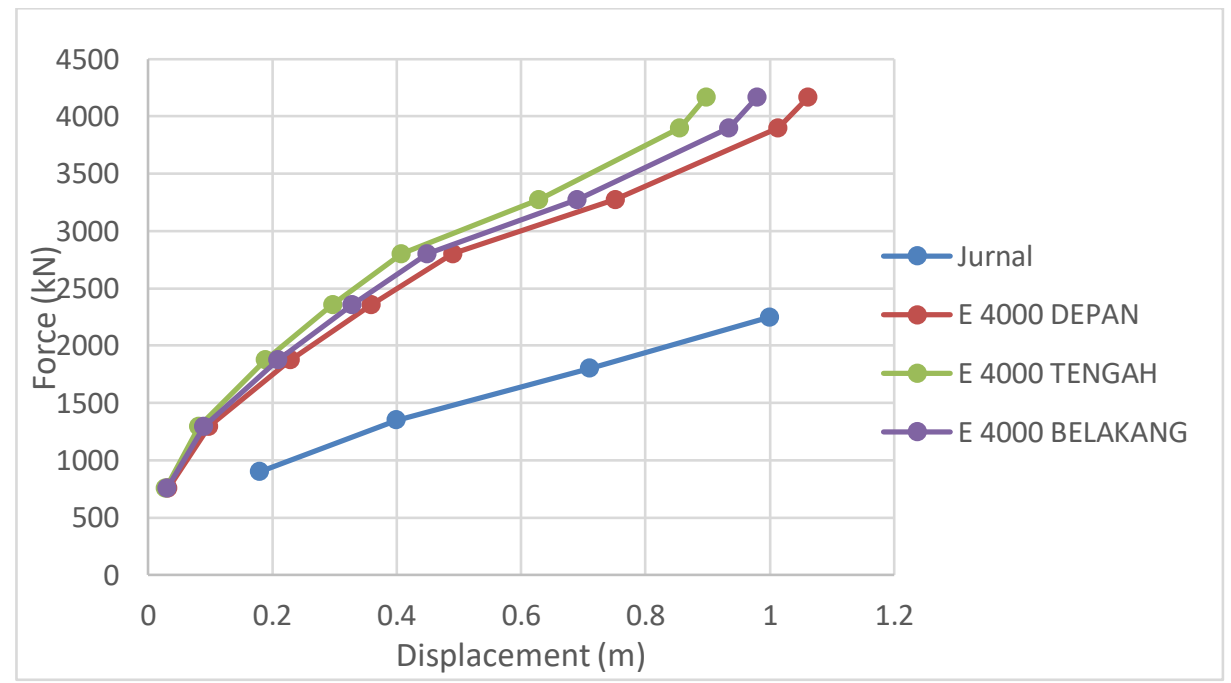

Gambar 7. Back analysis pushover 9 tiang dengan hardening soil model untuk tanah normally consolidated ( E tiang $=4000 \mathrm{kN} / \mathrm{m}^{2}$ )

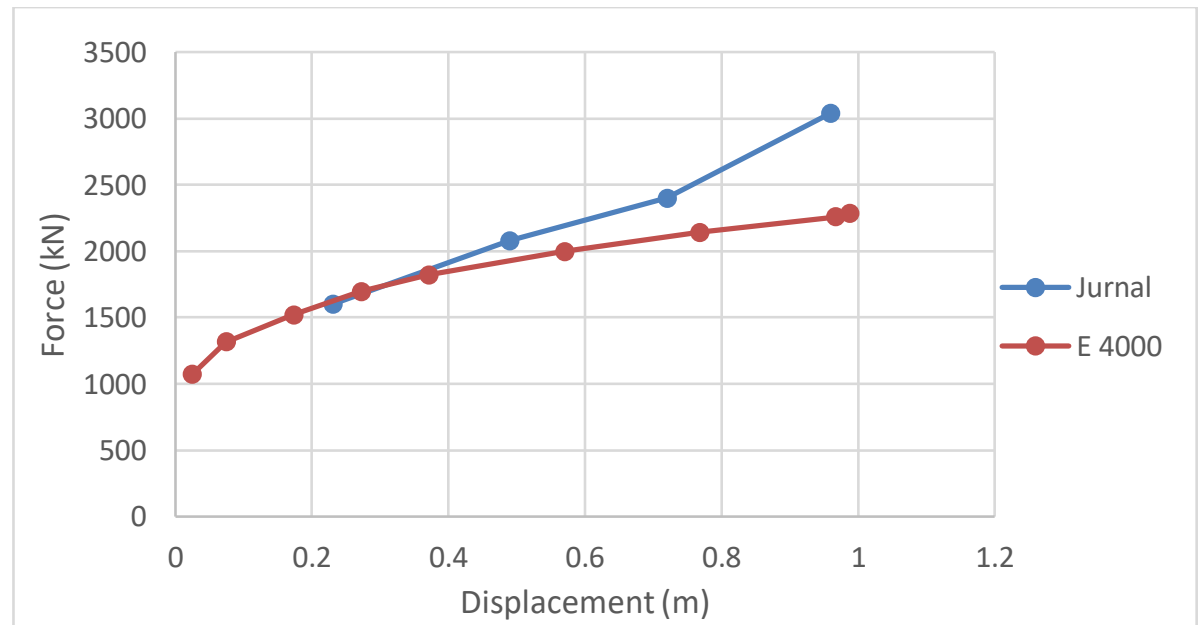

Gambar 8. Back analysis pushover 16 tiang dengan hardening soil model untuk tanah normally consolidated ( E tiang $=4000 \mathrm{kN} / \mathrm{m}^{2}$ ) 
Modelisasi Numerik Analisis Gaya Lateral pada Pile Cap di Darwin Halim, et al. Tanah Kohesif

Catatan: Pemodelan tanah hardening soil model untuk tanah overconsolidated dapat dilihat pada gambar 9 s/d 13.

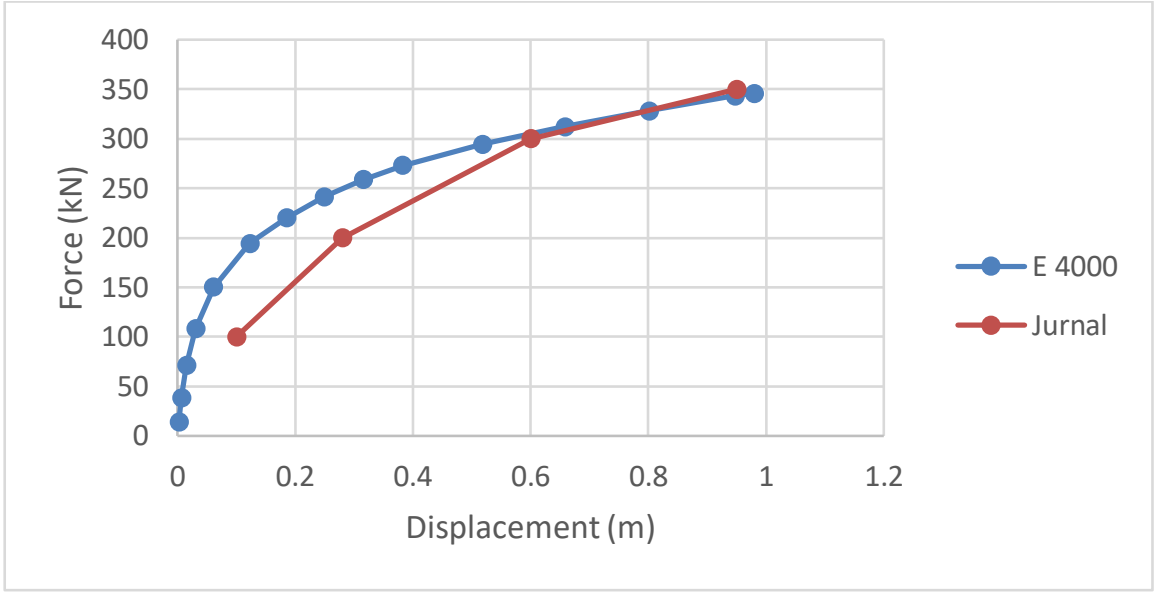

Gambar 9. Back analysis pushover 1 tiang dengan hardening soil model untuk tanah overconsolidated ( E tiang = $4000 \mathrm{kN} / \mathrm{m}^{2}$ )

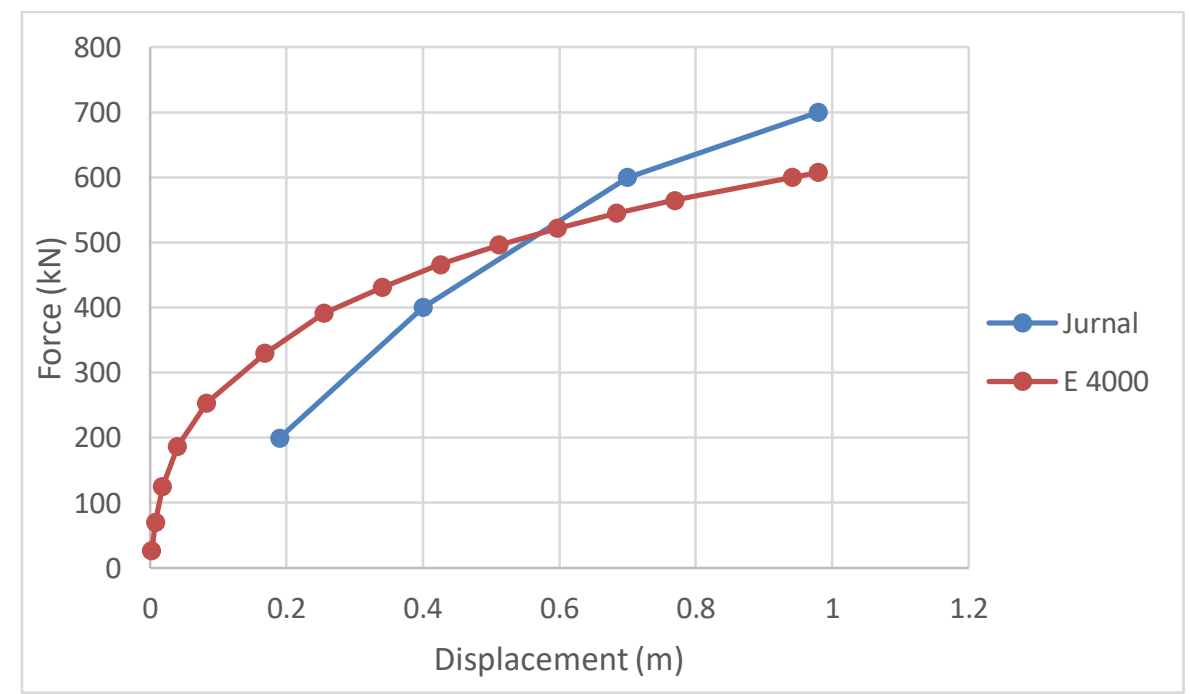

Gambar 10. Back analysis pushover 2 tiang dengan hardening soil model untuk tanah overconsolidated $(\mathrm{E}$ tiang $=$ $4000 \mathrm{kN} / \mathrm{m}^{2}$ ) 


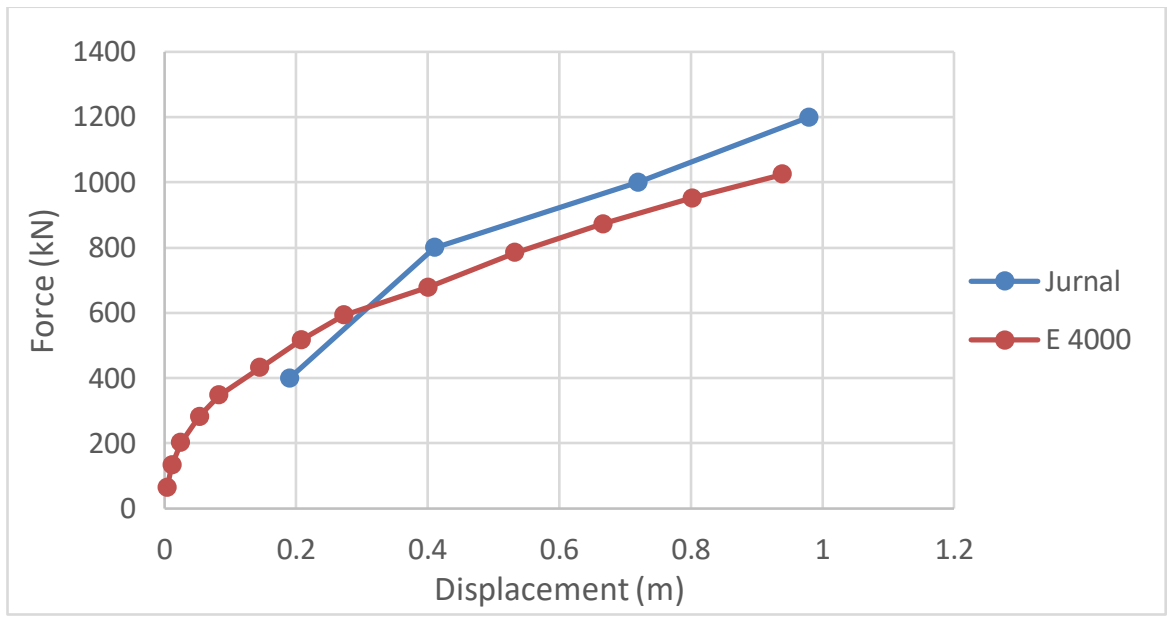

Gambar 11. Back analysis pushover 4 tiang dengan hardening soil model untuk tanah overconsolidated ( E tiang = $4000 \mathrm{kN} / \mathrm{m}^{2}$ )

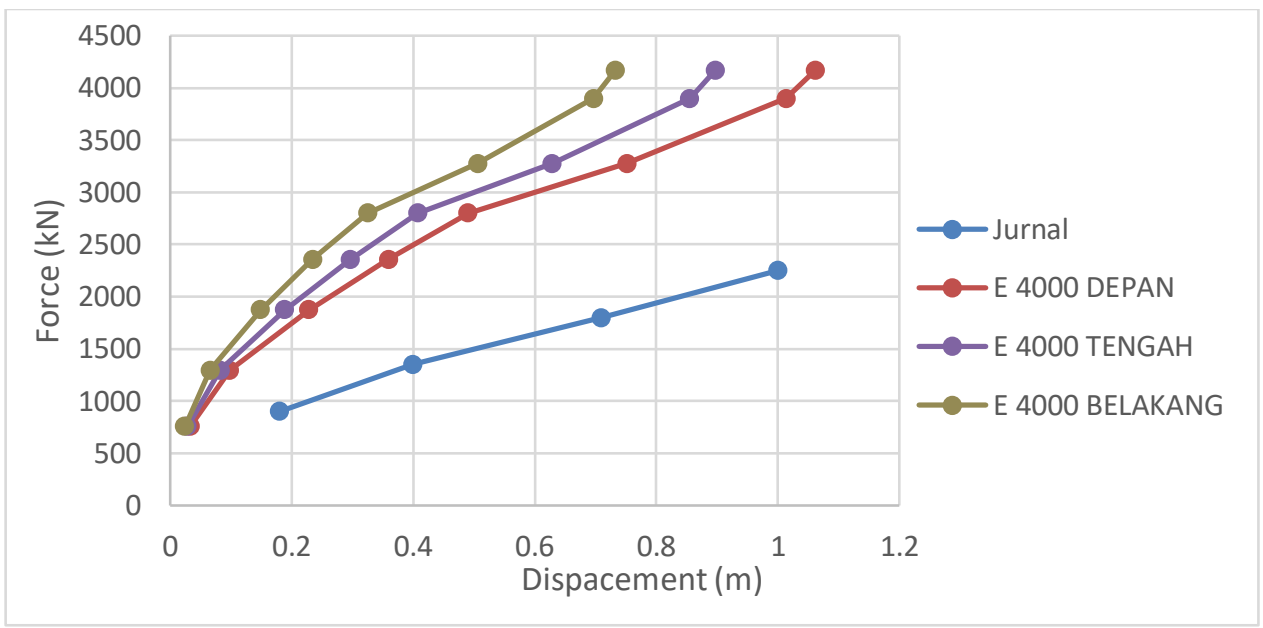

Gambar 12. Back analysis pushover 9 tiang dengan hardening soil Model untuk tanah overconsolidated $\left(\mathrm{E}\right.$ tiang $\left.=4000 \mathrm{kN} / \mathrm{m}^{2}\right)$

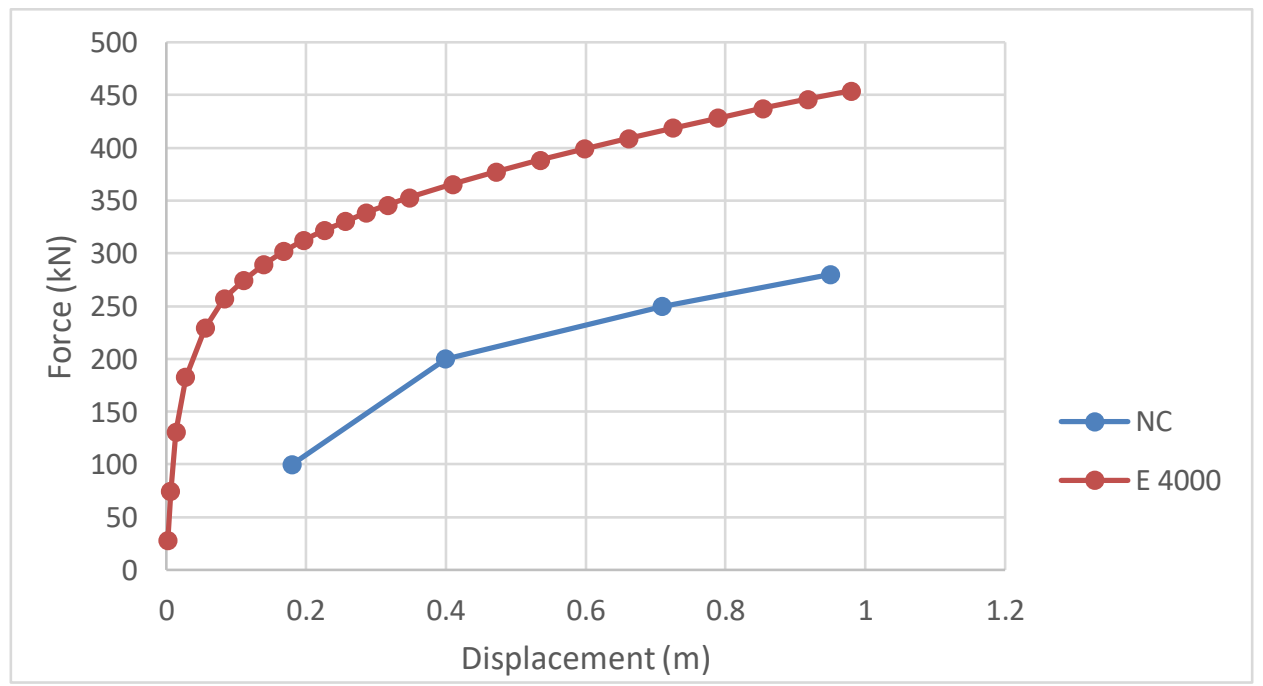

Gambar 13. Back analysis pushover 1 tiang dengan mohr coulomb model untuk tanah normally consolidated $\left(\mathrm{E}\right.$ tiang $\left.=4000 \mathrm{kN} / \mathrm{m}^{2}\right)$ 
Modelisasi Numerik Analisis Gaya Lateral pada Pile Cap di Darwin Halim, et al. Tanah Kohesif

Catatan: Pemodelan tanah mohr coulomb model untuk tanah normally consolidated dapat dilihat pada gambar 14 s/d 17.

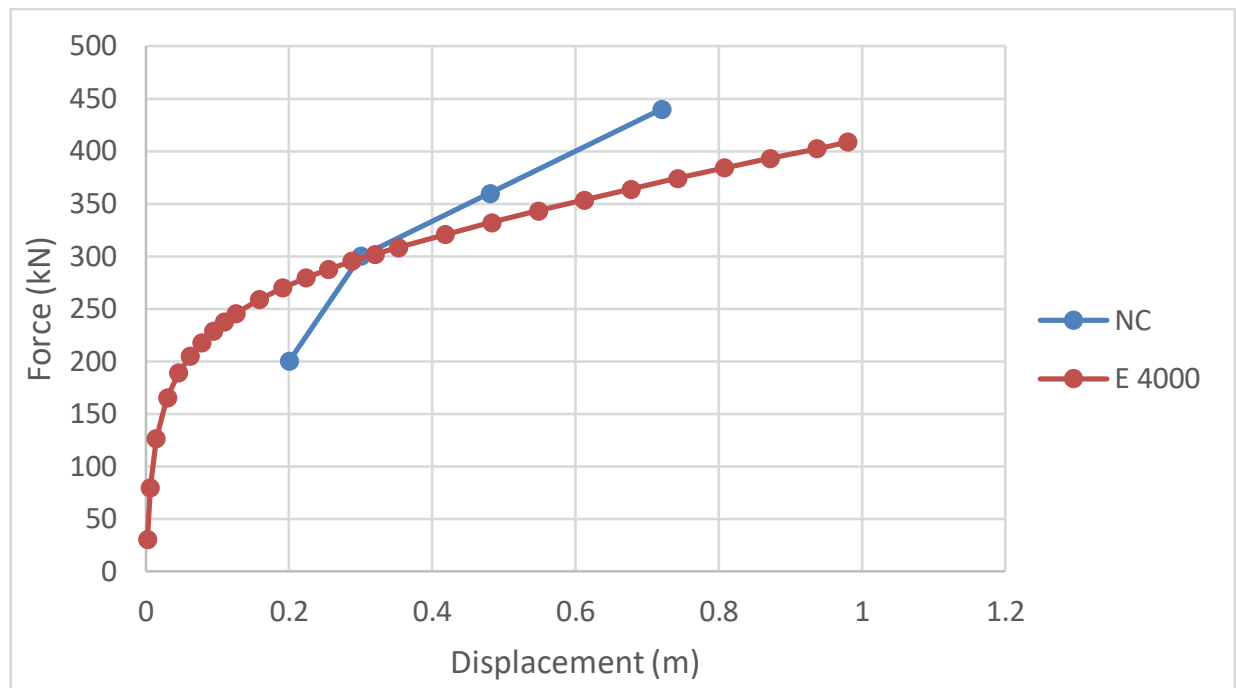

Gambar 14. Back analysis pushover 2 tiang dengan mohr coulomb model untuk tanah normally consolidated $\left(\mathrm{E}\right.$ tiang $\left.=4000 \mathrm{kN} / \mathrm{m}^{2}\right)$

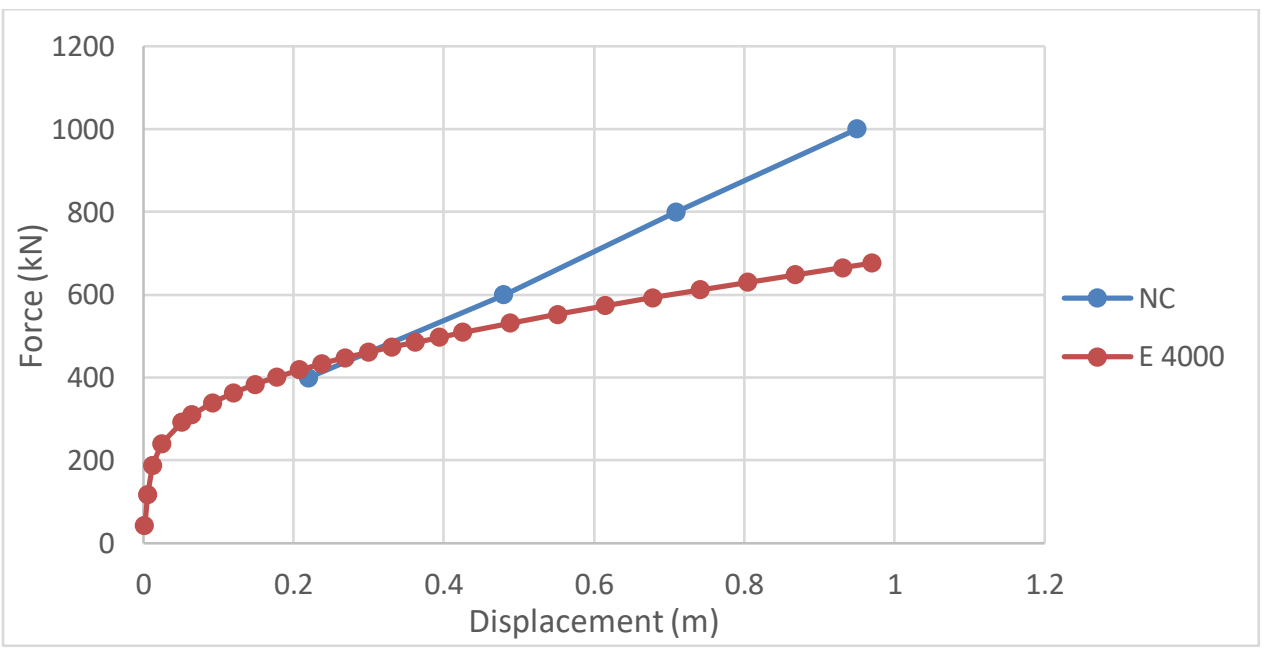

Gambar 15. Back analysis pushover 4 tiang dengan mohr coulomb model untuk tanah normally consolidated ( E tiang $=4000 \mathrm{kN} / \mathrm{m}^{2}$ ) 


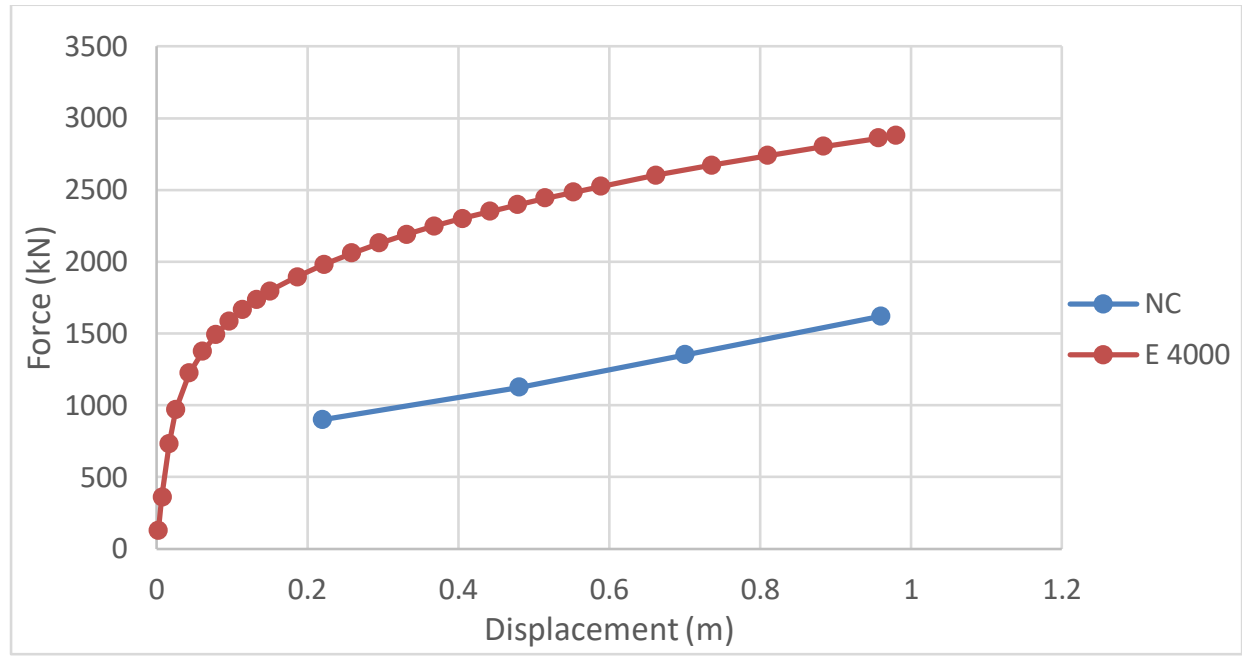

Gambar 16. Back analysis pushover 9 tiang dengan mohr coulomb model untuk tanah normally consolidated ( E tiang $=4000 \mathrm{kN} / \mathrm{m}^{2}$ )

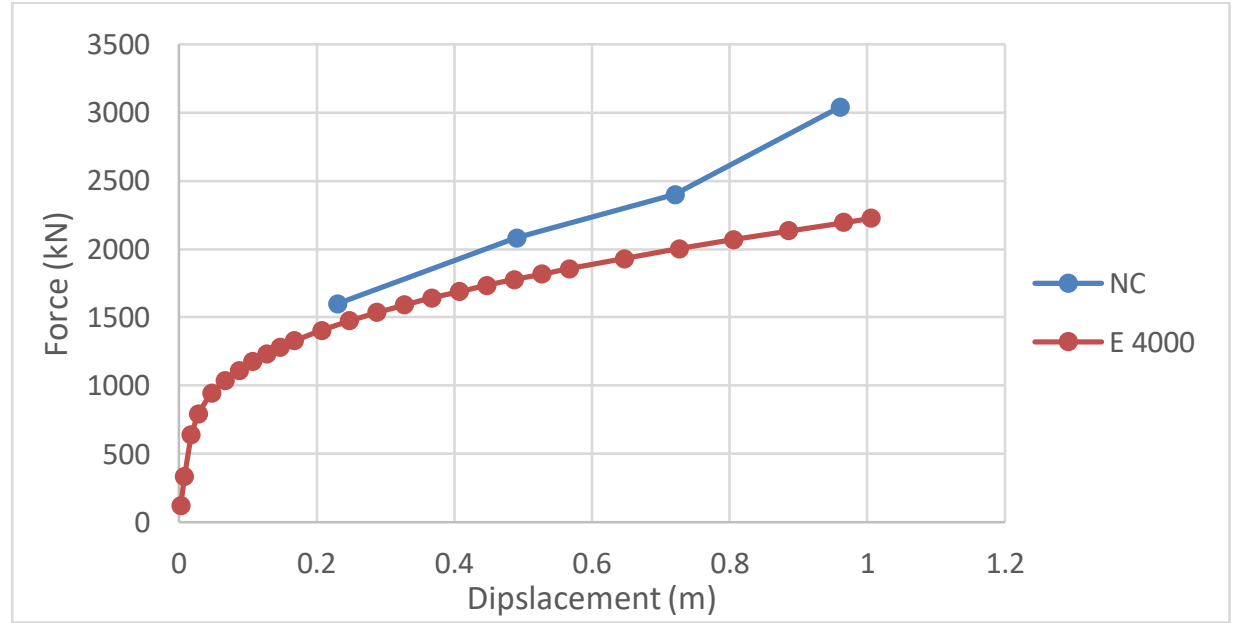

Gambar 17. Back analysis pushover 16 tiang dengan mohr coulomb model untuk tanah normally consolidated ( E tiang $=4000 \mathrm{kN} / \mathrm{m}^{2}$ )

Catatan: Pemodelan tanah mohr coulomb model untuk tanah overconsolidated dapat dilihat pada gambar 18 s/d 21. 
Modelisasi Numerik Analisis Gaya Lateral pada Pile Cap di

Darwin Halim, et al.

Tanah Kohesif

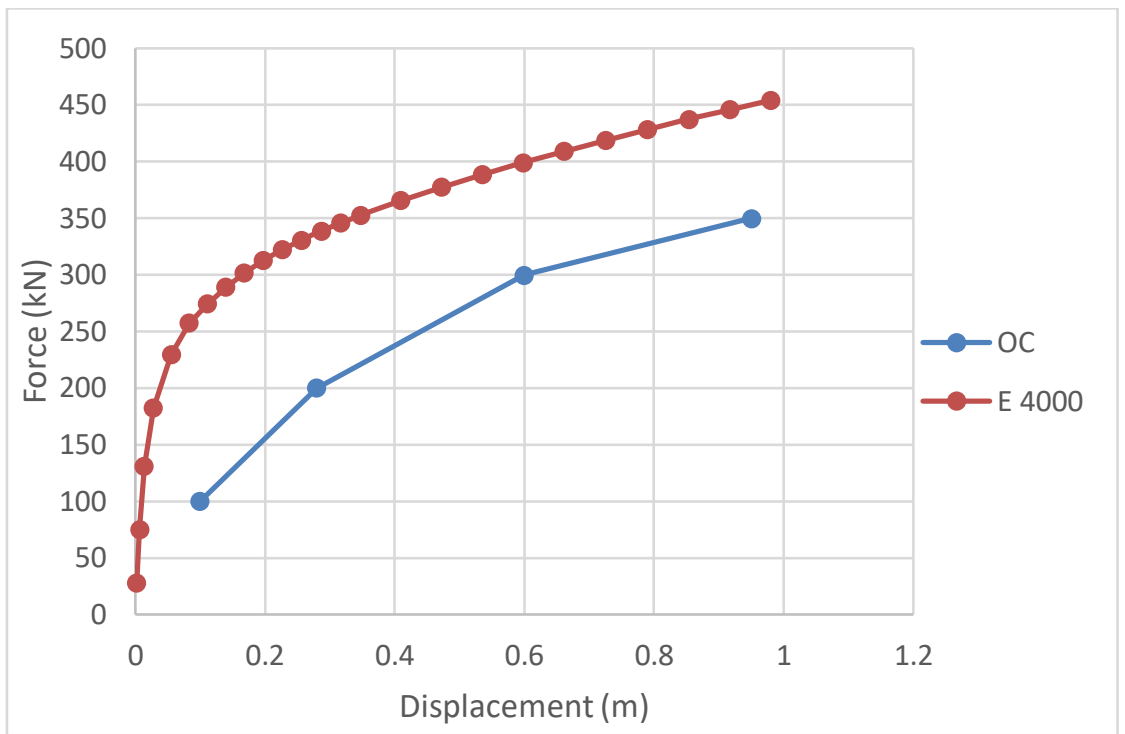

Gambar 18. Back analysis pushover 1 tiang dengan mohr coulomb model untuk tanah overconsolidated ( E tiang = $4000 \mathrm{kN} / \mathrm{m}^{2}$ )

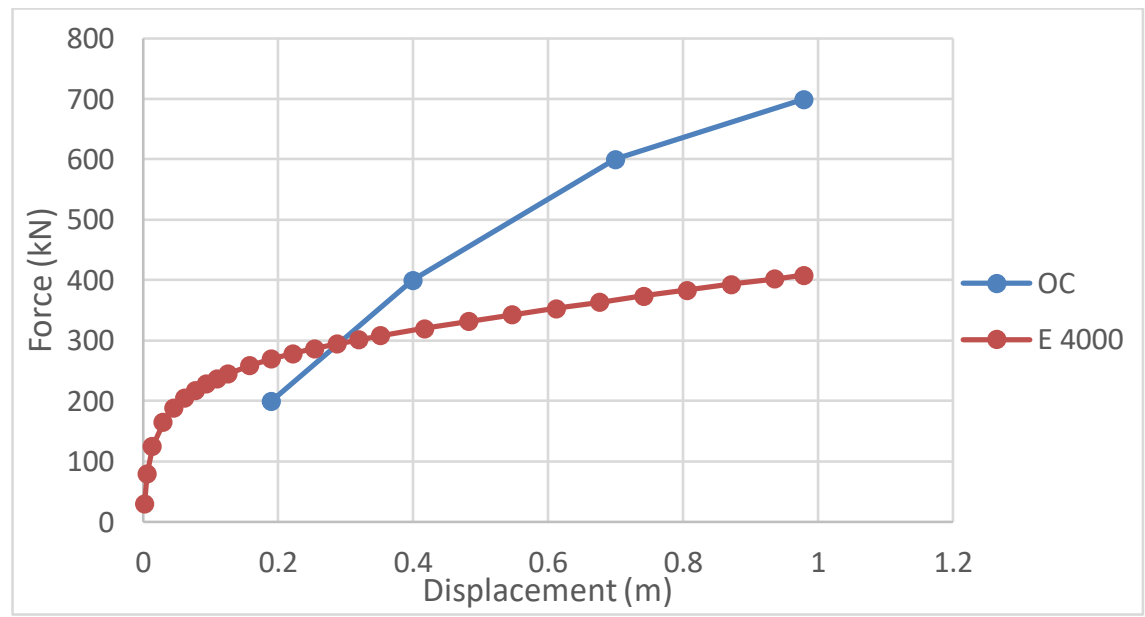

Gambar 19. Back analysis pushover 2 tiang dengan mohr coulomb model untuk tanah overconsolidated ( E tiang = $4000 \mathrm{kN} / \mathrm{m}^{2}$ )

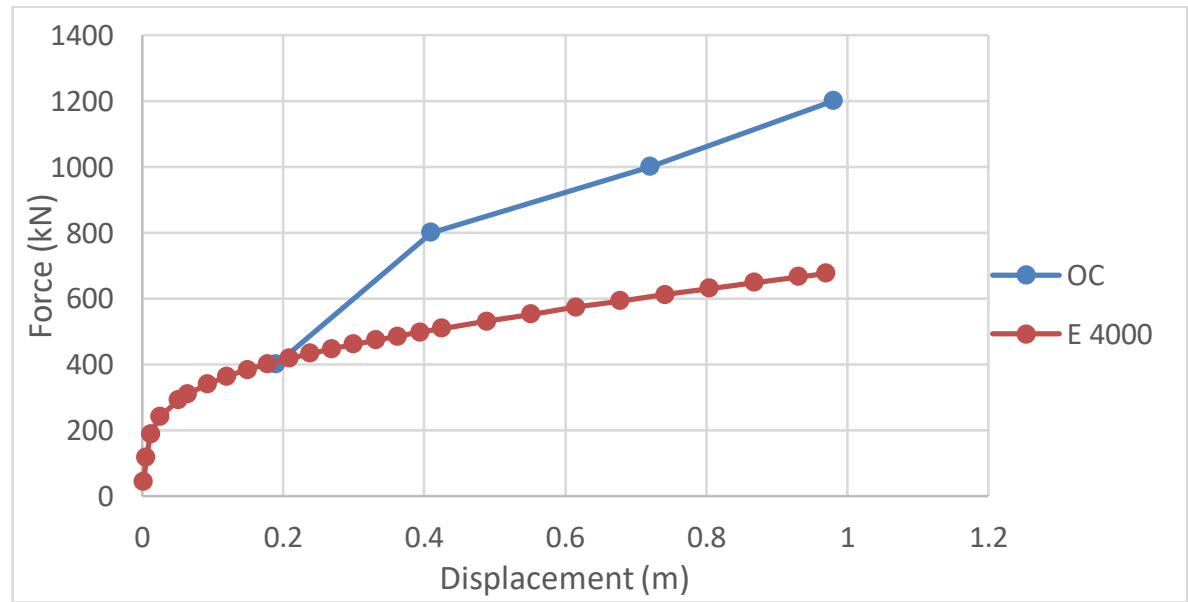

Gambar 20. Back analysis pushover 4 tiang dengan mohr coulomb model untuk tanah overconsolidated ( E tiang = $4000 \mathrm{kN} / \mathrm{m}^{2}$ ) 


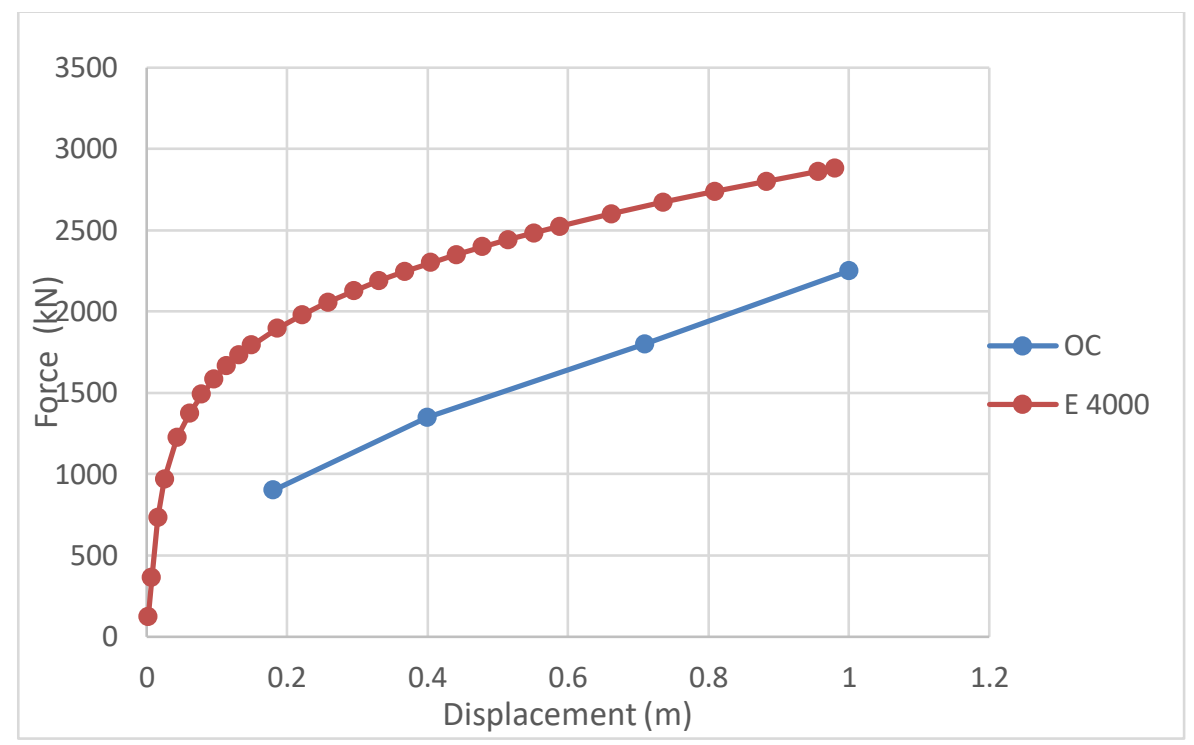

Gambar 21. Back analysis pushover 9 tiang dengan mohr coulomb model untuk tanah overconsolidated ( E tiang = $4000 \mathrm{kN} / \mathrm{m}^{2}$ )

\section{KESIMPULAN DAN SARAN}

\section{Kesimpulan}

Berdasarkan hasil analisis yang telah dilakukan, dapat disimpulkan bahwa:

1. Berdasarkan hasil analisis, semakin banyak jumlah tiang dalam suatu kelompok tiang makan semakin besar displacement yang dapat terjadi pada masing-masing tiang.

2. Berdasarkan hasil analisis, penulis memutuskan bahwa analisis pada tiang yang berada di tanah kondisi Overconsolidated lebih baik daripada tanah yang berada di kondisi Normally Consolidated. Karena pada tanah kondisi Overconsolidated Clay, berdasarkan hasil analisis, displacement yang terjadi lebih memiliki pola meningkat yang lebih teratur sesuai dengan jumlah tiang dan hasil nilai displacement yang lebih mendekati dan sesuai dengan nilai displacement pada jurnal "Centrifuge Model Study of Laterally Loaded Pile Groups in Clay".

3. Berdasarkan hasil analisis, penulis memutuskan bahwa analisis menggunakan model Hardening Soil lebih baik dari pada model Mohr Coulomb. Karena memiliki nilai displacement yang lebih mendekati dan sesuai dengan nilai displacement pada jurnal "Centrifuge Model Study of Laterally Loaded Pile Groups in Clay".

\section{Saran}

Berdasarkan hasil analisis yang telah dilakukan, adapun saran untuk melengkapi studi ini adalah dapat dilakukan penelitian yang lebih lanjut dengan ukuran dan jarak tiang yang berbeda serta dengan advanced model yang lain seperti, HS small model, dan dapat juga dilakukan analisis dengan pola kegagalan tiang leading dan trailing.

\section{DAFTAR PUSTAKA}

Ilyas, T, et al. "Journal of Geotechinal and Geoenvironmental Engineering ASCE." Centrifuge Model Study of Laterally Loaded Pile Groups (2004): 274-283.

McVay, M., L. Zhang and T \& Lai,P Molnit. "Journal of Geotechnical and Geoenvironment Engineering, ASCE." Centrifuge Testing of Large Laterally Loaded Pile Groups in Sands (1998): 1019-1025. 
Modelisasi Numerik Analisis Gaya Lateral pada Pile Cap di

Darwin Halim, et al.

Tanah Kohesif 